University of Nebraska - Lincoln

DigitalCommons@University of Nebraska - Lincoln

March 2000

\title{
Prediction of crude fat content of longissimus muscle of beef using the ratio of fat area calculated from computer image analysis: Comparison of regression equations for prediction using different input devices at different stations
}

K. Kuchida

Obihiro University of Agriculture and Veterinary Medicine, Obihiro, 080-8555, Japan

S. Kono

Hiroshima Prefectural Animal Experiment Station, Shoubara, 727-0023, Japan

K. Konishi

Ouu Station, National Livestock Breeding Center, Shichinohe-machi, 039-2567, Japan

L. Dale Van Vleck

University of Nebraska-Lincoln, dvan-vleck1@unl.edu

M. Suzuki

Obihiro University of Agriculture and Veterinary Medicine, Obihiro, 080-8555, Japan

See next page for additional authors

Follow this and additional works at: https://digitalcommons.unl.edu/animalscifacpub

Part of the Animal Sciences Commons

Kuchida, K.; Kono, S.; Konishi, K.; Van Vleck, L. Dale; Suzuki, M.; and Miyoshi, S., "Prediction of crude fat content of longissimus muscle of beef using the ratio of fat area calculated from computer image analysis: Comparison of regression equations for prediction using different input devices at different stations" (2000). Faculty Papers and Publications in Animal Science. 220.

https://digitalcommons.unl.edu/animalscifacpub/220

This Article is brought to you for free and open access by the Animal Science Department at DigitalCommons@University of Nebraska - Lincoln. It has been accepted for inclusion in Faculty Papers and Publications in Animal Science by an authorized administrator of DigitalCommons@University of Nebraska - Lincoln. 


\section{Authors}

K. Kuchida, S. Kono, K. Konishi, L. Dale Van Vleck, M. Suzuki, and S. Miyoshi 


\title{
Prediction of crude fat content of longissimus muscle of beef using the ratio of fat area calculated from computer image analysis: Comparison of regression equations for prediction using different input devices at different stations
}

\author{
K. Kuchida*, S. Kono $\dagger$, K. Konishił, L. D. Van Vleck§, M. Suzuki*, and S. Miyoshi* \\ *Obihiro University of Agriculture and Veterinary Medicine, Obihiro, 080-8555, Japan; $†$ Hiroshima Prefectural \\ Animal Experiment Station, Shoubara, 727-0023, Japan; †Ouu Station, National Livestock Breeding Center, \\ Shichinohe-machi, 039-2567, Japan; and §Roman L. Hruska U.S. Meat Animal Research Center, \\ ARS, USDA, Lincoln, NE 68583-0908
}

\begin{abstract}
Crude fat content of longissimus (ribeye) muscle of beef cattle was predicted from a ratio of fat area (RFA) to area of ribeye muscle calculated from computer image analysis (CIA). Cross sections of 64 ribeyes taken from the $6-7^{\text {th }}$ rib from cattle at experiment station A and cross sections of 94 ribeyes taken from the $6-7^{\text {th }}$ rib from cattle at Experiment Station B were used in this study. Slices (1 to $1.5 \mathrm{~cm}$ in thickness) of just the Longissimus dorsi were homogenized and sampled for chemical estimation of crude fat content using petroleum ether. Crude fat content as determined from chemical analysis was used as the true estimate of fat content. A CCD (charge-coupled device) camera was used as the input device at Experiment Station A, and a single-lens reflex camera was used at Experiment Station B to photograph ribeyes for CIA. The contour comparison method, which assigns a threshold value for each marbling particle, was used to obtain accurate binarization in this study. Minimum and maximum of chemical measurements of crude fat were 2.1 and
\end{abstract}

$39.8 \%$, and for CIA calculation of the RFA were 6.1 and $56.8 \%$, respectively. This range covered almost the complete range of the beef marbling standard used in carcass grading in Japan. The equation for the regression of the crude fat content (Y) on RFA (X) calculated from CIA for all of the data was $\mathrm{Y}=.793 \mathrm{X}-3.04$ with $\mathrm{r}^{2}=.96$. Regression equations for prediction of crude fat percentage from RFA taking into consideration the effect of experiment station were $\mathrm{Y}=.741 \mathrm{X}-2.22$ with $\mathrm{r}^{2}=.91$ for Experiment Station A, and $\mathrm{Y}=.782 \mathrm{X}-2.54$ with $\mathrm{r}^{2}=.91$ for Experiment Station B. Analysis of covariance showed that the effects of experiment stations on intercepts and slopes were not significant $(P$ $>$.10). The ranges of differences between actual and predicted crude fat content from the prediction equation that was calculated without consideration of the effect of station were -6.4 to $4.0 \%$. CIA of cross sections of the ribeye muscle seems to have potential for prediction of crude fat content.

Key Words: Animal Fat, Carcasses, Imagery

(C2000 American Society of Animal Science. All rights reserved.

J. Anim. Sci. 2000. 78:799-803

\section{Introduction}

Generally, marbling is evaluated visually at the time of grading, but crude fat content in beef is often used to evaluate marbling more objectively (Savell et al., 1986; Herring et al., 1998). However, sampling of meat for chemical analysis reduces the carcass value and requires a great deal of labor for processing.

Nondestructive methods, such as near-infrared reflectance spectroscopy (NIRS), have been used to predict crude fat. High accuracy of predicted crude fat content with NIRS was reported for minced and cut meat (Roberts et al., 1987; Mitsumoto et al., 1991).

Received November 2, 1998.

Accepted September 14, 1999.
The availability of information processing equipment has afforded accurate image analysis. The most important step in image analysis is to obtain a correct threshold value that divides lean and marbling. Kuchida et al. (1997b) developed software for image analysis using the contour comparison method. This software draws contours of marbling particles for a specified area on the computer screen that displays the original color image of the ribeye area. The ratio of fat area (RFA) to area of ribeye muscle obtained with this program could be used as a linear covariate to predict crude fat percentage in ribeye muscle with high precision $\left(\mathrm{r}^{2}=\right.$ .91 ) and accuracy (error of prediction within $\pm 3 \%$; Kuchida et al., 1998). However, the image data in that study were taken by CCD camera at only one laboratory, and prediction error when using a traditional film camera, the type that is widely used to photograph meat, was 
not evaluated. Moreover, the range of crude fat percentage of their material was too small for Wagyu cattle. The purposes of this study were 1) to analyze image data taken from two input devices (i.e., a CCD camera and a film camera) and 2) to use regression equations to predict crude fat percentage from RFA in the cross section of the ribeye.

\section{Materials and Methods}

\section{Materials and Photographing Method at Experiment Station A}

The materials were 64 longissimus muscles (ribeye) and their cross sections from a cut at the 6-7th rib, which is the standard location for measuring marbling in Japan. These were obtained from 35 Japanese Black, 6 Angus, and $23 \mathrm{~F}_{1}$ crossbred of Japanese Black sires and foreign breed dams. After slaughter, the materials (about $0.5 \mathrm{~kg}$ ) were vacuum-packaged and transported to Ouu Station, National Livestock Breeding Center (Shichinohe-machi, Japan) under low temperature storage (at $0^{\circ} \mathrm{C}$, not frozen). A CCD camera (Sony: DXC930; Tokyo, Japan) was used to photograph the cross-section at the $6-7^{\text {th }}$ rib after the sample was kept for at least $12 \mathrm{~h}$ in a refrigerator at $0^{\circ} \mathrm{C}$. Care was taken to ensure that the temperature of the meat surface did not increase during photographing. The CCD camera was mounted perpendicular to the meat surface. A zoom lens (Sony: VCL712BXEA) was used to take as large an image as possible. The image resolution from this equipment was $512 \times 480$ pixels (about 740 kilobytes for a bitmap file).

To determine crude fat percentage, the whole ribeye of each sample was separated and trimmed from the intermusclar fat, and then each ribeye was sliced to $1 \mathrm{~cm}$ in thickness and minced for analysis. Chemical measurement of the crude fat percentage was performed using the ether extraction method (AOAC, 1990).

\section{Materials and Photographing Method in Experiment Station B}

The materials used were 94 longissimus muscles and their cross sections from a cut at the 6-7th rib from Japanese Black beef bought at retail markets. Photographs of the ribeye were taken using a single-lens reflex camera (Minolta: $2707 \mathrm{si}$; Osaka, Japan) with as large an image as possible of the ribeye area at Hiroshima Prefectural Animal Experiment Station (Shoubara-shi, Japan). The sample was kept for at least $3 \mathrm{~h}$ in a refrigerator at $4{ }^{\circ} \mathrm{C}$. A strobe (Minolta: Program Flash 5400HS) with soft lighting (Minolta: Soft Lighting Set) was used from an angle of $45^{\circ}$ to the surface to avoid irregular reflection on the surface of ribeye. Photographs were taken within 5 min after removal from the refrigerator to ensure that the temperature of the meat surface did not increase much during photo- graphing. The camera was mounted perpendicular to the meat surface. Images were printed on photographic print paper $(12 \times 8 \mathrm{~cm})$ and were scanned using a color image scanner (Epson: GT-8500; Tokyo, Japan). Resolution from this equipment was about $800 \times 600$ pixels (about 1.6 megabytes for a bitmap file). Crude fat was determined by the same method as previously described.

\section{Image Analysis}

The program for the computer image analysis (CIA) was written in Visual C++ (Microsoft, Redmond, WA), which is the 32-bit application development language under the Windows NT operating system.

The greatest influence on the precision of calculation of marbling percentage is the process of converting a color image to a binary image ( 0 or 1$)$. This process divides the color image into two values (i.e., 0 or 1 to indicate lean and fat, respectively). Discriminant analysis (Otsu, 1980), which is generally used for automatically converting the color image to a binary image, may result in over- or underestimation due to the lack of uniformity of lighting, if only one threshold value is used in the conversion for the whole ribeye area. To avoid this error, an adaptive converting method (Takagi and Shimoda, 1991) has been proposed that mechanically divides the whole image into several partitions, with calculation of threshold values for each partition. However, the brightness of the marbling particle depends not only on the illumination by reflected light, but also on size of marbling particle. Thus, it is impossible to obtain accurate RFA if the calculation is done separately for each partition.

The contour-comparing method (Kuchida et al., 1997b), which assigned a threshold value for each marbling particle (if the particle was very large with irregular contours, the particle was divided into several areas), was used to obtain accurate binarization in this study. Contours of marbling particles are automatically drawn for the specified area on the computer screen that was displaying the original color image of the ribeye area. If the contours are judged to be wrong, it is possible to adjust them until they agree with those of the color image. The coincidence between drawn contours and contours seen on the color image is judged macroscopically. Each pixel has 0 to 255 signals for red, blue, and green components in this system. The green component is used for binarization because the variance of the green component was the largest for this photographic situation.

The subject of the image analysis of this study was the inside of the longissimus muscle. A contour line of longissimus muscle was manually drawn by the operator using drawing software (Adobe Photoshop, Adobe Systems Inc., Seattle, WA) before the image analysis process. Particles with small areas of less than $.01 \mathrm{~cm}^{2}$ were excluded in the analysis for the purpose of reducing noise caused by binarization. 
Table 1. Unadjusted means and standard deviations for rib-eye area, crude fat content, and ratio of fat area by experiment stations

\begin{tabular}{|c|c|c|c|c|c|c|}
\hline & \multicolumn{3}{|c|}{ Station A $(\mathrm{n}=64)$} & \multicolumn{3}{|c|}{ Station B $(\mathrm{n}=94)$} \\
\hline & Mean \pm SD & Minimum & Maximum & Mean $\pm \mathrm{SD}$ & Minimum & Maximum \\
\hline Ribeye area, $\mathrm{cm}^{2}$ & $41.3 \pm 8.7$ & 21.8 & 59.4 & $50.1 \pm 6.1$ & 37.3 & 66.7 \\
\hline Crude fat, $\%$ & $11.8 \pm 4.4$ & 2.1 & 27.1 & $24.7 \pm 6.7$ & 9.6 & 39.8 \\
\hline Ratio of fat area, $\%$ & $19.0 \pm 5.7$ & 6.1 & 36.1 & $34.9 \pm 8.1$ & 13.0 & 56.8 \\
\hline
\end{tabular}

\section{Statistical Analysis}

The mathematical model used to predict crude fat content from RFA calculated by CIA is

$$
\mathrm{Y}=\mathrm{aX}+\mathrm{b}
$$

[Model 1]

where $\mathrm{Y}$ is crude fat content, $\mathrm{a}$ is the slope of the linear regression equation of crude fat content on RFA, $\mathrm{X}$ is RFA of each sample, and b is the intercept.

Homogeneity of slopes and intercepts of the regression equations by station was examined using the following model:

$$
\mathrm{Y}_{\mathrm{i}}=\mathrm{a}_{\mathrm{i}} \mathrm{X}_{\mathrm{i}}+\mathrm{b}_{\mathrm{i}}
$$

[Model 2]

where, $Y_{i}$ is crude fat content of the $i^{i t h}$ experiment station, $a_{i}$ is the partial regression coefficient for the $i^{\text {th }}$ experiment station, $X_{i}$ is RFA from the $i^{\text {th }}$ experiment station, and $b_{i}$ is the intercept of the $i^{\text {th }}$ experiment station.

The effects of breed groups were not included in the mathematical models, although several breed groups were used at Station A. Effects due to breed groups have been shown to be not significant (Kuchida et al., 1998). The GLM procedure of SAS (1989) was used for statistical analysis.

\section{Results and Discussion}

Table 1 contains unadjusted statistics for ribeye area, chemical measurements of crude fat, and CIA calculations of the RFA for each station. Marbling scores in Japan are assigned using the Beef Marbling Standard (BMS), which has 12 marbling levels. Kuchida et al. (1997a) reported that RFA for BMS No. 1 and No. 12 were about 0 and $50 \%$, respectively. The range of RFA for beef samples from Experiment Stations A and B covered the range of RFA for all levels of BMS.

The size of the image data from Experiment Station A (760 kilobytes; bitmap file) was different from the size of the image data file from Experiment Station B (1.6 megabytes; bitmap file). Kuchida et al. (1997b) examined the difference in calculated RFA due to resolution using image data with three resolutions that were processed from one original image. They found no differences among the RFA calculated from image data files of three sizes: 170 kilobytes, 980 kilobytes and 2.5 megabytes (bitmap files).
The relationship between chemically measured crude fat percentage and RFA calculated with CIA is plotted in Figure 1. The regression equation (Model 1) obtained for prediction of crude fat percentage from RFA without and with accounting for the effect of experiment station were

$$
\begin{aligned}
\mathrm{Y}= & .793 \mathrm{X}-3.04 \text { with } \mathrm{r}^{2}=.96 \text { for overall, } \\
\mathrm{Y}= & .741 \mathrm{X}-2.22 \text { with } \mathrm{r}^{2}=.91 \text { for Experiment } \\
& \text { Station A, and } \\
\mathrm{Y}= & .782 \mathrm{X}-2.54 \text { with } \mathrm{r}^{2}=.91 \text { for Experiment } \\
& \text { Station B. }
\end{aligned}
$$

These prediction equations indicated that the relationship between chemically analyzed crude fat content and RFA with CIA was linear, because quadratic and cubic terms were not significant. Analysis of covariance using Model 2 showed effects of experiment stations on intercepts (Station A, -2.22 , Station B, -2.54) and on slopes (Station A, 0.741, Station B, 0.782) were not significant $(P>0.10)$.

Prediction errors were obtained by subtracting actual crude fat content from predicted crude fat content using the prediction equations (Model 1 or Model 2) and are summarized in Table 2. The range of prediction error from Model 1, which did not consider of the effect of station, were from -2.2 to $3.0 \%$ for Experiment Station $\mathrm{A}$ and from -6.4 to $4.0 \%$ for Experiment Station B, respectively. Ranges from Model 2, which considered the effect of station, were -2.5 to $2.8 \%$ for Experiment Station A and -6.4 to $4.0 \%$ for Experiment Station B.

The method of predicting crude fat content described in this study was not influenced by experiment station or input devices, because differences between intercepts and slopes due to stations with Model 2 were not significant $(P>0.10)$. Ranges of prediction errors from Model 1 and Model 2 also were similar.

The RFA increases about 3\% for each level of the standard scale from BMS No. 1 to No. 10 and increases about 10\% for each level from BMS No. 10 to No. 12 (Kuchida et al., 1997b). The proportion of prediction errors from Model 1 that were within $\pm 3.0 \%$ was 0.930 .

Possible causes of prediction error were examined for the ribeyes $(n=11)$ with prediction errors from Model 1 larger than $3 \%$. These cross sections were found to contain large marbling particles with these areas greater than $4.0 \mathrm{~cm}^{2}$ and to be in contact with the periphery of ribeye for eight of the 11 samples. 


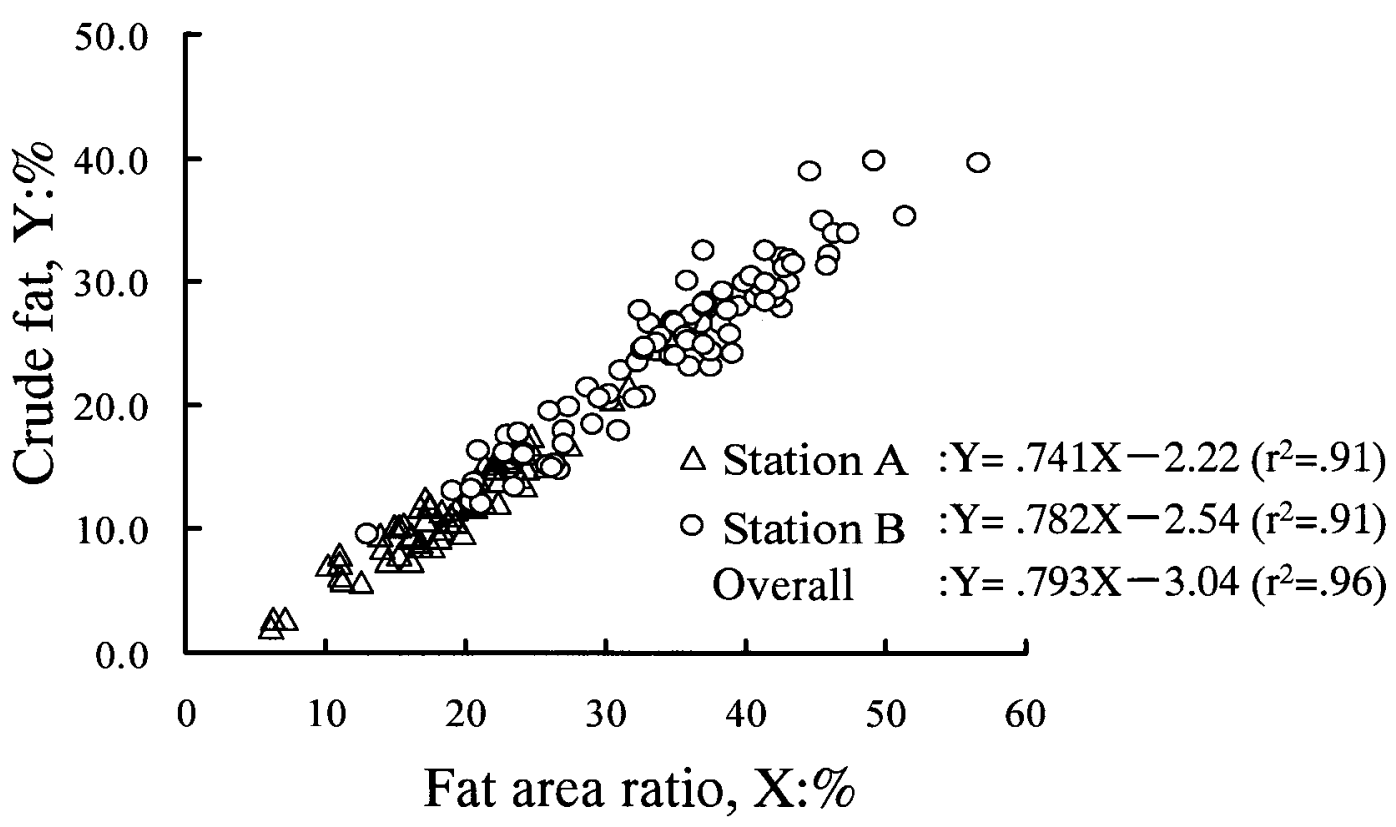

Figure 1. Relationship between crude fat content measured with the ether extraction method and fat area ratio calculated with computer image analysis of the ribeye image from two experiment stations.

For prediction of crude fat from the RFA calculated with CIA, we assumed that RFA on the surface of the ribeye was the constant through a 1 - to $1.5-\mathrm{cm}$ ) thickness, but, in reality, the ratio is not constant. Some masses of fat could not be seen on the surface of the photographed ribeye. Violation of this assumption might be one of the primary causes of prediction error. Accuracy of estimation might be improved if more thinly sliced meat is used.

Kuchida et al. (1999) attempted to evaluate marbling score with CIA. The Japanese Marbling Standard was highly correlated to RFA by image analysis with $\mathrm{r}^{2}=$ 0.47 . They were able to predict the Japanese Marbling Standard using several measures from CIA (e.g., fineness and distribution of marbling within longissimus muscle). According to their results, RFA is a main effect for Japanese MS, although Japanese MS would be affected by other image analysis traits.

Table 2. Summary of basic statistics of errors ${ }^{\mathrm{a}}$ of prediction of crude fat content from ratio of fat area using two prediction equations

\begin{tabular}{lccccc}
\hline \hline & \multicolumn{2}{c}{ Model $1^{\mathrm{b}}$} & & \multicolumn{2}{c}{ Model 2 } \\
\cline { 2 - 3 } \cline { 5 - 6 } \cline { 5 - 6 } & Station A & Station B & & Station A & Station B \\
\hline Mean, \% & -.17 & .11 & & .01 & -.01 \\
Standard & & & & 1.31 & 2.05 \\
$\quad$ deviation, \% & 1.34 & 2.05 & & -2.81 & -4.04 \\
Minimum, \% & -3.02 & -3.96 & & 2.53 & 6.43 \\
Maximum, \% & 2.18 & 6.44 & & \\
\hline
\end{tabular}

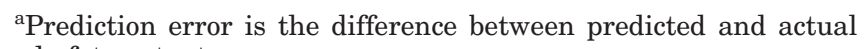
crude fat content.

${ }^{\mathrm{b}}$ Model 1 did not account for the effect of station.

${ }^{\mathrm{c}}$ Model 2 was calculated taking into consideration the effects of stations.

\section{Implications}

This study showed that combinations of input devices, photographic techniques, or size of image data file were not different for prediction of fat content from ratio of fat area to total area of a cross section of the longissimus muscle. With this method, the cross section of the carcass must be photographed in a perpendicular direction. This drawback could be solved by improvement in input devices for photographing the cross section of the ribeye. Advantages of this method are that no special device is needed and a photograph taken of the ribeye area in a past examination can be used. If computer image analysis could be used to gather data for marbling evaluations from progeny testing and feeding trials, the crude fat content prediction with computer image analysis could be a reference standard for degree of marbling.

\section{Literature Cited}

AOAC. 1990. Official Methods of Analysis (15th Ed.). Association of Official Analytical Chemists. Arlington, VA.

Herring, W. O., L. A. Kriese, J. K. Bertrand, and J. Crouch. 1998. Comparison of four real-time ultrasound systems that predict intramuscular fat in beef cattle. J. Anim. Sci. 76:364-370.

Kuchida K., K. Konishi, M. Suzuki, and S. Miyoshi. 1998. Prediction of the crude fat contents in ribeye muscle of beef using the fat area ratio calculated by computer image analysis. Anim. Sci. Technol. (Jpn.) 69:655-658.

Kuchida K., A. Kurihara, M. Suzuki, and S. Miyoshi 1997a. Computer image analysis method for evaluation of marbling of ribeye area. Anim. Sci. Technol. (Jpn.) 68:878-882.

Kuchida K., A. Kurihara, M. Suzuki, and S. Miyoshi. 1997b. Development of accurate method for measuring fat percentage on ribeye area by computer image analysis. Anim. Sci. Technol. (Jpn.) 68:853-859. 
Kuchida, K., S. Tsuruta, L. D. Van Vleck, M. Suzuki, and S. Miyoshi. 1999. Prediction method of beef marbling standard number using parameters obtained from image analysis for beef ribeye. Anim. Sci. J. 70:107-112.

Mitsumoto, M., S. Maeda, T. Mitsuhashi, and S. Ozawa. 1991. Nearinfrared spectroscopy determination of physical and chemical characteristics in beef cuts. J. Food Sci. 56:1493-1496.

Otsu, N. 1980. An automatic threshold selection method based on discriminant and least squares criteria. The transactions of the institute of Electronics and Communication Engineers of Japan. J63-D:349-356.
Roberts, C. A., P. L. Houghton, K. J. Moore, K. A. MacMillan, and R. P. Lemenager. 1987. Analysis of bovine udder, plate and viscera using near infrared reflectance spectroscopy. J. Anim. Sci. 65:278-281.

SAS. 1989. SAS/STAT User's Guide (Version 6, 4th Ed.). SAS Inst. Inc., Cary NC.

Savell, J. W., H. R. Cross, and G. C. Smith. 1986. Percentage ether extractable fat and moisture content of beef longissimus muscle as related to USDA marbling score. J. Food Sci. 51:838-840.

Takagi, M., and H. Shimoda. 1991. Handbook of Image Analysis (1st Ed.) Tokyo Univ. Press, Tokyo, Japan. 